\title{
¿FUERON INFLACIONARIAS LAS FINANZAS ESTATALES EN EL SIGLO XVIII? UNA NUEVA INTERPRETACION DE LOS VALES REALES *
}

EUGENE N. WHITE

Las finanzas de los gobiernos de fines del siglo xvin en España han sido con frecuencia calificadas de inherentemente inflacionarias. Los crónicos déficit presupuestarios, consecuencia de una base fiscal débil y fuertes gastos de guerra, se han considerado el móvil que forzó al gobierno a la emisión de papel moneda. Pese a ser ésta en gran medida una descripción aplicable a los últimos años del siglo, cuando empezaban a desintegrarse las finanzas del Antiguo Régimen, el gobierno consiguió resolver sus problemas hacendísticos con mayor éxito del que, por lo general, se le concede.

El principal instrumento de las deficitarias finanzas de los últimos veinte años del siglo xviı fueron los vales reales, la primera forma de papel moneda en España. Aunque los historiadores los han considerado como un simple expediente de financiación, la creación de los vales reales estuvo gobernada por unos principios que eran comunes a otros países de Europa y a las colonias británicas de América. Los assignats de la Francia revolucionaria, así como los bills of credit y el papel moneda de las colonias americanas, tenían las mismas características que los vales reales ${ }^{1}$. Los gobiernos recurrían con frecuencia a la impresión de dinero, pero por lo general lo consideraban como una medida fiscal expeditiva, de carácter extraordinario, exigida por las inmensas necesidades de la guerra. El papel moneda era tan sólo un expediente temporal que podía retirarse de la circulación en fecha posterior. Para destacar la índole de la obligación contraída, los gobiernos fijaban planes de amortización en el momento de emisión del papel moneda. Si estos programas se

* En la elaboración de este artículo he contraído mi mayor deuda con Leandro Prados de la Escosura, que me sugirió que comparara este episodio de la historia monetaria española con los assignats franceses que yo estudiaba. Quisiera también expresar mi agradecimiento a Hugh Rockoff, Bruce Smith y los participantes en el seminario del Centro Ortega y Gasset por sus observaciones.

- Aunque el carácter y la historia de los vales reales han sido examinados por historiadores económicos españoles, no se ha estudiado la semejanza entre los vales y otros tipos de papel moneda del siglo xviII. Véanse Herr (1977), Plaza Prieto (1975) y Vicens Vives y Nadal Oller (1979). 
cumplían fielmente, los grandes incrementos en oferta monetaria, que en condiciones normales habrían producido inflación, parecen haber tenido un efecto relativamente menor en los niveles de precios. En el primer decenio y medio de su emisión, los vales reales no afectaron seriamente la estabilidad de los precios. Sólo cuando se abandonaron los planes de amortización se desplomó el valor de los vales reales.

A primera vista, es difícil explicar el efecto de los vales reales sobre el nivel de los precios. El aumento de este tipo de dinero no es un buen mecanismo de predicción de las tasas de inflación, indicio de que la simple teoría cuantitativa del dinero es insuficiente. No es éste un problema infrecuente, y las progresivas dificultades de los teóricos monetarios en sus intentos de explicar la inflación les han inducido a buscar teorías alternativas. Neil Wallace ha presentado un nuevo paradigma ${ }^{2}$, mostrando que, en ciertas circunstancias, los efectos inflacionarios de un incremento en la oferta monetaria pueden quedar perfectamente compensados por una promesa de futuros impuestos que eleve la demanda de moneda. Esto se debe a que los efectos contradictorios de la previsión pública de futuros pagos contributivos anulan el efecto expansionista inmediato de la política monetaria elevando la demanda de dinero. Las consecuencias inflacionarias de una emisión de moneda dependen, pues, de cómo se haya armonizado con la política fiscal.

Es difícil someter a prueba la hipótesis de Wallace, porque son pocos los episodios de la historia reciente en que se haya concedido un respaldo fiscal explícito a la política monetaria ${ }^{3}$. Los estudios sobre las colonias británicas en América realizados por Bruce Smith y Elmus Wicker nos han proporcionado los primeros ensayos de la hipótesis de Wallace ${ }^{4}$. Al reexaminar los limitados datos disponibles sobre dinero y precios para las diversas colonias, parecen haber resuelto el clásico problema de la historia monetaria de dichas colonias que hace referencia al por qué los grandes incrementos en papel moneda no dispararon una rápida inflación ${ }^{5}$. Smith y Wicker comprobaron que cuando el papel moneda estaba firmemente respaldado por impuestos, la inflación era escasa, independientemente de la cantidad de papel moneda emitida. Sin embargo, cuando dicho compromiso no se contraía o no se cumplía se producía la inflación.

Las características y la historia de los vales reales sugieren que su éxito y posterior fracaso pueden explicarse mejor en términos de la hipótesis de

\footnotetext{
2 Wallace (1981).

${ }^{3}$ Sargent (1982) utiliza la teoría de Wallace para explicar el fin de la hiperinflación alemana.

4 B. Smith $(1984,1985 a, 1985$ b) y Wicker (1985).

3 Véase West (1978) para un test econométrico de la inaplicabilidad de la teoría cuantitativa simple a las colonias británicas de América.
} 
Wallace. Además, la experiencia española con el papel moneda puede proporcionar una mejor verificación de esta hipótesis, ya que los datos sobre precios son superiores a los existentes para las colonias británicas de América ${ }^{6}$. Este trabajo examina la historia de los vales reales, en primer lugar, centrándose en cómo las diferentes actitudes gubernamentales hacia sus compromisos de amortización afectaron al potencial inflacionario de este papel moneda. Concluye con un test de regresión de la hipótesis de Wallace que pone de manifiesto la esencial corrección de la teoría y la política monetarias del siglo xvirr.

\section{Origen y caracteristicas de los vales reales}

Cuando Carlos III declaró la guerra a los ingleses en abril de 1779, la situación financiera de la Corona era satisfactoria, pero no fuerte. La llegada indemne de metales del Nuevo Mundo en 1779 y un préstamo de Amsterdam permitieron al gobierno continuar la guerra sin grandes cambios de política. Pero en el verano de 1789 empezaron a escasear los fondos. Los Cinco Gremios Mayores prometieron reunir un préstamo a corto plazo de 30 millones de reales de vellón, pero sólo pudieron entregar la mitad de esta cantidad al gobierno. Se recaudaron algunos nuevos tributos ${ }^{7}$; pero, temeroso de que el aumento de impuestos pudiera haçer impopular esta guerra, el gobierno aceptó una novedosa propuesta de un sindicato de financieros nacionales y extranjeros. Estos se ofrecieron a anticiparle al gobierno 9 millones de pesos en moneda y letras de cambio si éste pagaba dicha cantidad con 9,9 millones de pesos en vales reales ${ }^{8}$. Su propuesta fue aceptada y, el 20 de septiembre de 1780 , Carlos III autorizó a la Tesorería a enviar los vales reales a aquel sindicato.

Los vales reales se emitieron en denominaciones de 600 pesos, y una tasa anual de interés del 4 por 100 . El interés se calculó sin dificultad a razón de, aproximadamente, 1 real de vellón diario 9 . Los vales reales serían admisibles a la par y devengaban intereses para todo tipo de contribución, y serían moneda legal para toda clase de transacciones, excepto para pagos salariales y comercio al detalle. Como observara Earl J. Hamilton, esta última estipulación era superflua, dado que la mínima denominación superaba con mucho las rentas anuales de la mayor parte de la población ${ }^{10}$. Para evitar su posible falsi-

- Los índices de precios de la América colonial están limitados a unos cuantos productos, con frecuencia sólo artículos de exportación. Hay, pues, una gran diferencia con los indices de precios construidos por Hamilton (1947).

7 Artola (1982), p. 369.

- Hamilton (1944), p. 37, y Hamilton (1945), p. 99.

- En este período, 600 pesos equivalían a unos 9.000 reales de vellón ( 1 peso $=15$ reales de vellón y 2 maravedís, siendo 34 maravedís $=1$ real de vellón), lo cual resulta en 360 reales anuales un interés del 4 por 100.

${ }_{10}$ Hamilton (1947), p. 79. 
ficación, los vales debían ser presentados anualmente a su vencimiento para ser cambiados por otros nuevos. Además, sólo podían circular endosados por sus propietarios. La última persona en firmarlos era legalmente responsable si el billete resultaba ser una falsificación. Estas medidas tan severas parecen haber disuadido a los falsificadores, pues son escasas las referencias a problemas de esta índole.

El gobierno prometió también retirar una vigésima parte del papel emitido todos los años. Aunque el primer ministro, conde de Floridablanca, aspiraba a constituir un fondo o reserva de amortización, el único respaldo de los vales reales era el crédito general de la Corona ". Probablemente, la mejor expresión de las intenciones del gobierno y de sus ideas monetarias se encuentre en la obra de José Alonso Ortiz Ensayo sobre la Moneda-Papel, de $1796^{12}$. Pese a no ser favorable a una frecuente emisión de papel moneda por parte del Estado, Alonso Ortiz sostenía que, en situaciones públicas de emergencia, era más conveniente que el gobierno emitiera dinero antes que intentar un aumento extraordinario de impuestos de difícil recaudación. Ahora bien, para que el público aceptara este papel moneda, el gobierno tendría que ir amortizándolo gradualmente con posterioridad mediante un ligero aumento del nivel tributario.

Los vales reales se asemejaban mucho a otros tipos de papel moneda emitidos en el siglo xviIr. En las colonias británicas de Norteamérica, el papel moneda era emitido por las tesorerías coloniales y los bancos hipotecarios, con denominaciones altas unas veces y bajas otras. El papel moneda se declaraba, por lo general, moneda legal, admisible para impuestos y deudas particulares, pero no estaba pensado como moneda fiduciaria puramente. Los gobiernos coloniales reservaban futuras recaudaciones fiscales para la amortización de billetes de la tesorería, y los billetes de los bancos territoriales se retiraban al irse devolviendo las hipotecas ${ }^{13}$. Los assignats franceses también tenían algunos rasgos en común con los vales reales. Emitidos primeramente cuando el gobierno no podía ya financiar su déficit con préstamos, los assignats eran billetes de denominación alta que devengaban un 3 por 100 de interés. Eran moneda de curso legal, y garantizaba su amortización la futura venta de tierras confiscadas a la Iglesia. En posteriores emisiones de assignats no se fijó un interés explícito y se imprimieron también denominaciones menores ${ }^{14}$. En Francia, y en algunas colonias americanas, no pudo evitarse la inflación porque

" Hamilton (1944), pp. 39-40.

12 José Alonso Ortiz, traductor de La riqueza de las naciones, mezcla las opiniones de Adam Smith sobre el dinero con razonamientos intelectuales a favor de la política de su poderoso protector, Diego María de Gardoqui, secretario del Despacho de Hacienda, Fernández Marugán y Schwartz (1977), p. 422.

13 B. Smith (1985), pp. 540-541.

14 Harris (1930), White (1985). 
se eliminó el respaldo fiscal de estos billetes; pero en la mayor parte de las colonias americanas que emitieron papel moneda en estas condiciones no se produjo una inflación apreciable, pese a que sus gobiernos habían incrementado mucho sus existencias monetarias.

Vales reales, assignats y el dinero colonial americano compartían unas características de las que podría decirse que no responden a la definición de dinero. Tendían a emitirse con denominaciones altas y devengaban intereses, haciéndolos más parecidos a bonos ${ }^{15}$. Sin embargo, conviene recordar que la definición fundamental de dinero incluye hoy día en muchos países valores que producen interés. Más aún, la emisión de billetes de denominación alta era consecuencia de la errónea convicción del siglo xvirI de que el dinero sólo era seguro y no inflacionario si se emitía en grandes denominaciones que limitaran su uso a los comerciantes. Adam Smith consideraba que la emisión de cualquier papel de valor inferior a 5 libras esterlinas tendría el efecto de inducir la salida del país, o la ocultación, de todo el dinero en metálico ${ }^{16}$. Su seguidor español, Alonso Ortiz, formuló una argumentación similar al afirmar que los billetes de baja denominación podían producir inflación ${ }^{17}$. Lo que ocurriría con la excesiva emisión de billetes, de denominación elevada o pequeña, sería el incremento del valor del dinero en metálico y el aumento de los precios en términos del papel moneda. El uso de los vales reales de denominación alta estaba, en efecto, limitado a los comerciantes, pero, por lo general, sirvieron de medio de cambio para pagos públicos y privados ${ }^{18}$.

\section{Los vales reales en la paz y en la guerra, 1779-1792}

La primera emisión de vales reales no fue suficiente. Los fuertes gastos del período de guerra, la no llegada de metales preciosos americanos y la caída

is Aunque se reafirma el carácter monetario de los vales reales, es cierto que eran muy similares a bonos. No es, por consiguiente, extraño que la proposición de Wallace sobre el papel moneda con respaldo fiscal contenga un corolario aplicable a los bonos en el artículo clásico de Barro (1974). Barro muestra que un déficit respaldado por bonos no es expansionista porque el público comprende que el incremento en la deuda gubernamental augura una subida en futuros impuestos.

16 A. Smith (1776-1937), p. 307.

17 Fernándeze Marugán y Schwartz (1977), p. 429. Alonso Ortiz podría haber hecho referencia a la experiencia francesa en apoyo de sus opiniones, pues la inflación aumentó dramáticamente tras haberse emitido assignats de baja denominación. Sin embargo, las colonias británicas en América proporcionan la evidencia contraria.

" Herr (1971), p. 40. Existen algunos datos sobre el uso de los vales reales. En Cádiz, los comerciantes pagaban parte de sus kempréstitos y donativos» en moneda y parte en vales en la década de 1790. Véase Tinoco Rubiales (1982), pp. 331-332, 344-346. El uso de vales reales como medio de cambio, incluso conllevando descuento, es muy similar al uso de los greenbacks durante la guerra civil americana. 
en la recepción de derechos de aduana forzaron al gobierno a procurar una segunda emisión. El 20 de marzo de 1781, la Corona autorizó el intercambio con un sindicato de 5.303 .100 pesos de vales reales (en billetes de 300 pesos) por 5 millones de pesos en plata y oro. La situación financiera del gobierno no mejoró, y el 20 de junio de 1782 se decretó una tercera emisión de 14.799.900 pesos. Esta última representaba una sustancial adición al presupuesto total de un año de la Corona ${ }^{19}$. El gobierno no intercambió esta emisión con sindicato alguno, sino que permitió al Tesoro que la utilizara para pagar los gastos directamente ${ }^{20}$.

En principio, la idea era que los vales reales se aceptaran a su valor nominal. Se dictaron castigos de exilio perpetuo y exclusión de toda transacción comercial con España para los transgresores, aunque estas penalizaciones no parecen haberse aplicado. La nueva emisión de vales reales y la incapacidad del gobierno para amortizarlos, como había prometido, fueron causa de que los vales circularan con descuento con relación a la plata ya en marzo de 1781. El cuadro 1 muestra la depreciación o apreciación de los vales reales con respecto a la plata. En 1782 se aceleró la depreciación de los vales y hacia octubre tenían un descuento del 22 por 100 . Enfrentado a la necesidad de apuntalar el valor de los vales reales, el gobierno aceptó la propuesta de Francisco de Cabarrús de crear un banco nacional. El Banco Nacional de San Carlos, constituido en junio de 1782, se idé con el fin de amortizar los vales en efectivo, descontar letras de cambio, hacer remesas extranjeras a la Corona y abastecer al Ejército y la Marina ${ }^{21}$.

El Banco Nacional de San Carlos abrió sus puertas en junio de 1783 e inició una limitadísima amortización de vales reales. Entre el 1 y el 30 de noviembre, el Banco amortizó 2.314 vales, restringiendo su cambio a uno por persona. Sorprendentemente, el valor de los vales aumentó con gran rapidez. En los meses de junio y julio su descuento era sólo del 2 al 3 por 100. Los directores del Banco afirmaron que su actuación era la responsable de la recuperación de los vales. Hamilton sostiene que ello no parece plausible, dado que tres cuartas partes del aumento de valor se produjo antes de marzo de 1783 , cuando los vales reales se aceptaron para la adquisición de valores bancarios, la primera medida destinada a elevar su valor. Hamilton atribuye su mejoría al pago puntual de intereses y a la reanudación de las importaciones de numerario a partir del 30 de enero de 1783. La opinión de Hamilton parece acertada, pues esta clase de operaciones mejoraron la situación financiera de la Corona, garantía última de los vales reales. El Banco Nacional abandonó

19 Herr (1977), p. 116.

20 Hamilton (1947), pp. 40-46; Hamilton (1945), p. 99.

21 Hamilton (1944), p. 38; Hamilton (1945), pp. 99-102. 
discretamente todo papel activo en la retirada de los vales reales después de sus primeras adquisiciones. Hacia 1800, este Banco tan sólo contaba con 73.210 pesos en vales, cantidad inferior a la que había inicialmente retirado y fracción mínima del total emitido ${ }^{2}$.

Los precios, como figura en el índice de precios de Hamilton del cuadro 1, ascendieron durante la guerra con Gran Bretaña. Dicho índice muestra un incremento en el nivel de precios de 102,8 en 1779 a 112,3 en 1782 . Hamilton atribuyó este aumento de precios a las excepcionalmente voluminosas importaciones de metales en 1779 , a la emisión de vales reales y a las malas cosechas. Uno de los problemas que plantea el uso de su índice de precios para calcular los efectos de los vales sobre los precios es que éstos se dan en moneda de cuenta, es decir, reales de vellón. Como los vales reales se depreciaron en relación a la plata y su poder adquisitivo relativo descendió, es importante calcular los precios en términos de vales.

Esto se ha realizado primeramente con la conversión del índice de precios a un índice en términos de plata, como sugería Hamilton, empleando sus datos sobre el valor del real de vellón en plata. El cuadro 1 refleja el agio o descuento de los vales reales en términos de plata. Se utilizó el punto medio de la variación conocida del agio para cada año. Este es, por necesidad, un cálculo tosco, pero en el que se hace el mejor uso posible de los escasos datos disponibles. La división del índice en plata por el valor en plata de los vales reales produce el índice de precios en vales reales del cuadro $1^{23}$. Este índice de precios demuestra que éstos aumentaron con mayor rapidez en términos de vales reales, elevándose de 106 en 1780 a 136 en 1782. El indice en plata refleja primordialmente los verdaderos efectos de la guerra sobre los precios, mientras que el incremento adicional del índice en papel moneda pone de manifiesto la función de los vales reales en el ascenso de los precios. Con el fin de la guerra con Gran Bretaña y la mejoría de las cosechas, los precios descendieron ligeramente y se estabilizaron durante los próximos años. Esto es aplicable a ambos índices de precios cuando creció la credibilidad del gobierno con respecto a la amortización de los vales reales.

Los precios se mantuvieron relativamente estables entre 1784 y 1790 , aumentando menos de un 10 por 100 . Los vales reales se cambiaban a la par o más en metálico a partir de 1783 , por lo que los incrementos de precios

22 Hamilton (1944), pp. 43-44, 57.

23 Hamilton (1947), pp. 77 y 232. Un maravedí equivalía a 0,357 gramos de plata fina en $1773-1785,0,3547$ en 1786 y 0,3524 en $1787-1800$. El índice del valor de la plats en un real de vellon o maravedí tiene, pues, tres valores: $1,0000,0,9936$ y 0,9871 , que reflejan las alteraciones en contenido de plata de las acuñaciones. Diviendo el índice del real de vellón entre este segundo índice se obtiene un índice de precios en términos de plata. 


\section{CUADRO 1}

Vales reales y precios en España, 1779-1819

\begin{tabular}{|c|c|c|c|c|}
\hline Años & $\begin{array}{c}\text { Vales reales } \\
\text { en circulación } \\
\text { (pesos de vellon) }\end{array}$ & $\begin{array}{l}\text { Indice de precios } \\
\text { de Hamilton para } \\
\text { Castilla la Nueva }\end{array}$ & $\begin{array}{l}\text { Indice de precios } \\
\text { en vales reales }\end{array}$ & $\begin{array}{c}\text { Margen de } \\
\text { descuento o prima } \\
\text { de los vales } \\
\text { en Madrid } \\
\text { (en porcentajes) }\end{array}$ \\
\hline 1779 & & 102,8 & & \\
\hline 1780 & 9.900 .000 & 105,8 & 105,8 & 0 \\
\hline 1781 & 15.203 .100 & 110,5 & 115,1 & -4 \\
\hline 1782 & 30.003 .000 & 112,3 & 136,1 & -13 a -22 \\
\hline 1783 & 30.003 .000 & 108,6 & 117,4 & -2 a -13 \\
\hline 1784 & 30.003 .000 & 111,9 & 109,7 & $+1,5 a+2,5$ \\
\hline 1785 & 29.002 .800 & 115,3 & 115,3 & 0 \\
\hline 1786 & 29.002 .800 & 117,0 & 117,8 & 0 \\
\hline 1787 & 29.002 .800 & 116,1 & 117,6 & 0 \\
\hline 1788 & 29.002 .800 & 118,1 & 119,6 & 0 \\
\hline 1789 & 29.002 .800 & 119,6 & 120,6 & $+0,5$ \\
\hline 1790 & 29.002 .800 & 127,7 & 128,8 & 0 \\
\hline 1791 & 28.968 .900 & 122,0 & 123,6 & 0 \\
\hline 1792 & 28.968 .900 & 125,1 & 125,5 & +1 \\
\hline 1793 & 28.968 .900 & 130,7 & 131,7 & $0 a+1$ \\
\hline 1794 & 62.969 .100 & 130,5 & 137,7 & $+1 a-9$ \\
\hline 1795 & 92.267 .100 & 139,3 & 159,5 & $-9 a-14$ \\
\hline 1796 & 90.533 .100 & 141,0 & 163,2 & -7 a $-18,5$ \\
\hline 1797 & 89.031 .900 & 155,5 & 189,2 & $-13,5$ a -20 \\
\hline 1798 & 86.747 .550 & 165,6 & 208,4 & $-17,5$ a $-21,5$ \\
\hline 1799 & 139.496 .850 & 154,6 & 274,8 & -43 \\
\hline 1800 & 139.496 .850 & 149,2 & 364,2 & -51 a -66 \\
\hline 1802 & & & & -75 \\
\hline 1806 & & & & -36 a -51 \\
\hline 1807 & & & & -41 a -51 \\
\hline 1808 & 125.735 .100 & & & -50 a -66 \\
\hline 1809 & & & & $-66 a-72$ \\
\hline 1810 & & & & $-68,5$ a -90 \\
\hline 1811 & & · & & $-90 a-96$ \\
\hline 1813 & & & & -56 \\
\hline 1819 & 115.524 .783 & & & -80 \\
\hline
\end{tabular}

FunNTEs: Los datos sobre valores reales en circulación provienen de Hamilton (1944) y Herr (1977). El índice de precios, de Hamilton (1947), p. 155. La información sobre el descuento y prima de los vales, de Hamilton (1944) y Canga Argüelles (1827), vol. I, p. 29 . El cálculo del índice de precios en vales reales se describe en el texto. 
reflejaban cambios auténticos. La primera y mayor amortización de vales reales de la década se produjo en julio de 1785 , cuando se retiraron por valor de 1.000.200 pesos ${ }^{24}$. El gobierno mantuvo la confianza en su papel moneda, pagando los intereses sin retraso y examinando cuidadosamente los billetes para evitar falsificaciones. La siguiente cantidad de cierta importancia en ser amortizada fue de 31.200 pesos de vales, en agosto de $1791^{25}$.

A Hamilton le extrañaba que, pese a que el gobierno no cumpliera su promesa de retirar una vigésima parte de la emisión de papel todos los años, los vales retuvieran su valor. Una explicación plausible sería que el público hubiera percibido los vales en términos de la hipótesis de Wallace: considerando el pago regular de intereses sobre los vales como prueba de que el gobierno estaba dispuesto a cumplir con su obligación de amortizarlos. Más aún, la credibilidad financiera del gobierno era bastante fuerte en la década de 1780. Artola ha calculado que, de 1783 a 1790 , el gobierno tuvo excedentes (rentas ordinarias y extraordinarias menos gastos) en cinco de estos años. El excedente acumulado de este período fue de 50,3 millones de reales de vellón. Hasta después de 1791 no empezaron a aumentar los déficit con rapidez ${ }^{20}$.

La guerra, 1793-1802 .

La guerra volvió a estallar en 1793 , esta vez con Francia, y aunque los ejércitos españoles lograron algunas victorias inmediatas, no se preveía un final próximo para esta contienda. Una vez más, las necesidades financieras obligaron al gobierno a emitir nuevos vales reales. En 1793, el Tesoro español tuvo unos gastos de 709 millones de reales de vellón y unos ingresos de sólo 548 millones ${ }^{27}$. Los gastos ascendieron hasta los 1.070 millones en 1796, mientras las rentas sumaron solamente 730 millones de reales de vellón.

${ }^{4}$ En aquel mismo mes se emitieron 4,2 millones de pesos en vales reales para financiar la terminación del Canal de Aragón. Más adelante, el 30 de diciembre de 1788, se emitieron nuevamente vales por valor de 2,4 millones de pesos para sufragar los costes de las obras del Real Canal de Tauste. Estos vales iban respaldados con la garantía de propiedades del canal, ingresos postales y un nuevo arancel sobre la lana. Hamilton (1944), pp. 40-46, y Hamilton (1945), p. 99. Estos vales se consideraron como un tipo distinto de billete y no se incluyeron en el análisis empírico mencionado. Su inclusión en otros tests no alteró los resultados, porque el volumen total de estas emisiones fue reducido.

${ }_{25}$ El 3 de marzo de 1791, la Compañía de Filipinas ofreció una emisión de 3.990 .000 vales. Estos vales tenían carácter monetario, pero sus intereses y su amortización quedaron bajo responsabilidad de la Compañia, y más parecían valores particulares. Estos vales se han excluido del cálculo del stock monetario. Aunque podría parecer sensato incluirlos, nunca fueron más que un componente relativamente pequeño. Hamilton (1944), p. 46.

${ }^{26}$ Artola (1982), p. 368.

27 Herr (1971), p. 41. 
Durante este período de cuatro años vinieron a acrecentar las rentas algunas medidas de excepción, como serían nuevos tributos, y subsidios y donaciones de comerciantes y clero, pero el déficit acumulado alcanzó un total de $1.269 \mathrm{mi}$ llones de reales de vellón. Este vacío se cubrió con un préstamo de 240 millones, negociados en 1795, y tres nuevas emisiones de vales reales por valor de 968 millones de reales de vellón. La primera de ellas, de 16,2 millones de pesos de vellón, obedeció a un Decreto del 1 de febrero de 1794. Otros dos Decretos siguieron a éste: uno de 18 millones, el 8 de septiembre de 1794, y otro de 30 millones, el 25 de febrero de 1795.

Las exigencias de la guerra causaron una subida de precios, y los precios en vales aumentaron aún más como reacción al empleo de unas finanzas inflacionarias. Pese a ello, el descenso en el valor de los vales reales y la subida de los precios parece leve, dado que el volumen total de vales que circulaba en 1795 era tres veces superior al de 1793. Una posible explicación de esta significativa divergencia entre crecimiento monetario y variación de precios puede residir en el auténtico esfuerzo que realizó el gobierno para otorgar a los vales un sólido respaldo fiscal. Para la primera emisión de 1794 se constituyó un fondo de amortización. Este debía recibir el 10 por 100 de todos los bienes y alcabalas municipales, así como unas tasas especiales sobre la exportación de numerario. El fondo de amortización se estableció en la Tesorería, pero quedó bajo la autoridad del Consejo de Castilla para garantizar que sus fondos se emplearan exclusivamente para pagar los intereses de los vales reales 0 amortizarlos ${ }^{28}$.

Cuando el gobierno se vio obligado a imprimir una segunda emisión de vales en aquel mismo año, se añadieron otros impuestos al fondo destinado a pagar sus intereses y retirarlos. Se incrementó la contribución sobre la sal, el papel sellado y las tierras, y entró en vigor un impuesto del 4 por 100 sobre los sueldos y jubilaciones de los funcionarios. Todo esto, junto a mayores donativos de la Iglesia, se asignó al fondo de amortización. La recaudación de estos impuestos se estimaba en 40 millones de reales de vellón, lo suficiente para retirar la totalidad de la emisión en un período de seis años. Con el fin de inspirar mayor confianza, se entregó la administración del fondo de amortización a una junta independiente del Ministerio de Hacienda. Una vez más, en el siguiente año, al emitirse más vales reales, se añadieron nuevas rentas al fondo extraídas de los beneficios vacantes de la Iglesia y de las Indias. Para destacar la calidad de su compromiso, el gobierno inició en 1796 la publicación de los ingresos anuales procedentes de la contribución asignada al fondo de amortización ${ }^{29}$. Como resultado de todas estas medidas, los inte-

2 Herr (1977), p. 117.

Hamilton (1944), pp. 51-53, 62. 
reses se pagaban con regularidad y se realizaron considerables amortizaciones en los tres años siguientes.

En julio de 1795, España acordó con Francia un tratado de paz independiente, irritando con ello a sus antiguos aliados. En octubre de 1796 se halló, una vez más, en guerra con Gran Bretaña. La destrucción de la Armada por parte de los ingleses en 1797 y el bloqueo de Cádiz produjeron un dramático descenso en derechos de aduana e importaciones de metálico, y hundieron en' la depresión a las industrias de exportación andaluzas. Las rentas totales de las posesiones de ultramar cayeron verticalmente desde 236,9 millones de reales de vellón en 1796 a 12,4 millones en $1797^{30}$. El estado deprimido de la economía y la ya gravosa presión tributaria tuvieron como consecuencia serios motines en Guadalajara y Sevilla, en 1797. La caída en los ingresos fiscales forzó al gobierno a recurrir una vez más al mercado de valores. La emisión de títulos por valor de 100 millones de reales de vellón al 5 por 100 , en julio de 1797, se vendió bien, pero, en noviembre, una nueva emisión de 60 millones fracasó ${ }^{31}$. Sin otra fuente alternativa de rentas, el gobierno echó mano del fondo de amortización en octubre de 1797, llevándose 9.412 .943 reales de vellón ${ }^{32}$.

Para hacer frente a la crisis financiera, el valido de Carlos IV, Manuel Godoy, nombró un nuevo equipo de ministros, entre los que figuraba Francisco de Saavedra como secretario del Tesoro. Saavedra, en un esfuerzo por restaurar la confianza en los vales reales, propuso que el fondo de amortización saliera del Tesoro y fuera independiente. El rey aceptó la propuesta, y en marzo de 1798 se estableció la Caja de Amortización, a la que se le asignaron algunas rentas de los impuestos municipales y ciertos ingresos eclesiásticos. El descuento de los vales descendió brevemente, pero la escasez de ingresos impidió que se restaurara la confianza. Un préstamo patriótico consiguió reunir tan sólo 1,5 millones de reales de vellón, y los motines de Asturias y Sevilla desaconsejaron un nuevo incremento de la contribución. La independencia de la Caja de Amortización resultó ficticia, y la mayoría de los fondos que se le habían asignado fueron consumidos por el Tesoro ${ }^{33}$.

Hacia el verano de 1798 , el gobierno estaba desesperado. Plenamente consciente de que la caída de Luis XVI había tenido su origen en la crisis financiera de la Corona, los consejeros de Carlos IV se temían lo peor. El nuevo secretario del Tesoro, Miguel Cayetano Soler, recomendó la venta de bienes

30 Canga Arguielles (1826), p. 59.

31 En abril de 1799 se retiraron los bonos no vendidos. Herr (1971), p. 43.

32 Hamilton (1944), p. 62.

33 Herr (1971), pp. 43-44, 82. Desde su creación en marzo de 1798 hasta su disolución en agosto de 1800 , la Caja de Amortización recibió fondos por valor de 568,3 millones de reales de vellón, pero sólo amortizó vales por valor de 39,8 millones de reales. 
eclesiásticos menores y el depósito de su producto en la Caja de Amortización. El rey aceptó esta propuesta y decretó la venta de ciertas tierras eclesiásticas en septiembre de 1798, iniciándose con ello la desamortización de los bienes eclesiásticos en España. Pero esta medida no consiguió solventar el dilema financiero de la Corona. En enero de 1799 se constituyó una comisión para la administración de las ventas de tierras, pero éstas fueron en un principio lentas, obligando a la Corona a recurrir a nuevas maniobras expeditivas. La Caja de Amortización enviaba la mayor parte de sus rentas al Tesoro, y en 1798 se retrasó el pago de intereses sobre los vales reales ${ }^{34}$.

Aunque se emitieron empréstitos con buena fortuna en España, en 1798, y en Holanda, en 1799, la Corona no conseguía, ni mediante bonos ni mediante impuestos, cubrir su déficit presupuestario. Careciendo de otras opciones, el gobierno se vio forzado a recurrir a la mayor emisión de vales hasta el momento -53.109 .300 pesos-, el 8 de abril de 1799. Aunque en noviembre se impusieron nuevos tributos a los municipios por valor de $300 \mathrm{mi}$ llones de reales y se restringió la amortización de vales, el gobierno no pudo mantener el pago de intereses ${ }^{35}$. Había a la sazón 139 millones de pesos en circulación. Esta era una cantidad superior al total de moneda acuñada en toda España durante los tres decenios precedentes ${ }^{36}$.

Este rápido aumento de dinero sin respaldo ocasionó una acelerada subida de precios. El gobierno se vio incapacitado para cumplir su compromiso de amortizar los vales simplemente porque la guerra había reducido drásticamente sus rentas mientras acrecentaba enormemente sus gastos. Al incrementarse progresivamente el descuento de los vales reales, el gobierno intentó apuntalar su valor. Haciendo responsables a los especuladores del elevado descuento, el 8 de abril de 1799, la Corona prohibió a toda persona, salvo los cambistas con licencia, que actuara como intermediario en las transferencias de vales. Se estudió también un complicado plan que pondría a la Iglesia a cargo de la retirada de vales, pero no fue adoptado. Finalmente, el 17 de julio de 1799, se prohibieron los contratos donde se estipularan pagos en metálico, y se hizo obligatoria la aceptación de vales a un descuento máximo del 6 por $100 \mathrm{La}$ aplicación de esto último resultó imposible y fue abandonada al año siguiente ${ }^{37}$. El descuento era ya superior al 50 por 100 .

En un nuevo intento de restaurar la confianza en los vales reales, se disolvió la Caja de Amortización y se estableció la Caja de Consolidación, el 30 de agosto de 1800. El objeto de estas medidas era dar apoyo a los vales, volviendo a pagar sus intereses regularmente y poder llegar a retirarlos. Entraron

\footnotetext{
34 Herr (1971), p. 44; Herr (1977), p. 117.

${ }^{33}$ Hamilton (1944), pp. 57, 64.

36 Hamilton (1947), p. 84.

3 Ibid., pp. 68, 71-72.
} 
en vigor nuevos impuestos de consumo para costear estos pagos ${ }^{38}$. Pese a que los datos sobre el descuento de los vales reales son escasos en estos años, al parecer, el gobierno no logró restaurar la confianza en ellos. La insuficiencia de las rentas percibidas de otras fuentes impulsó al gobierno a tratar la Caja de Consolidación como si fuera un segundo Tesoro, absorbiendo la mayor parte de sus ingresos y permitiendo que el descuento de los vales descendiera hasta un 75 por 100 en $1802^{39}$. El fin de la guerra no pudo ser más oportuno. La salud económica del gobierno se recuperó algo gracias a la reanudación de grandes envios de metales desde el Nuevo Mundo.

\section{Los vales reales y la desamortización eclesiástica}

Cuando se reiniciaron las hostilidades entre Francia y Gran Bretaña, en 1803, España se encontró en una situación incómoda. El Tratado de San Ildefonso de 1796 estipulaba que España suministrara ayuda militar a Francia. En sustitución de esta cláusula, Napoleón aceptó el pago de un subsidio mensual de 16 millones de reales de vellón ${ }^{40}$. Los ingleses se negaron a considerar a España neutral, y los ataques lanzados contra navíos españoles indujeron a Carlos IV a declararles la guerra. Al subsidio francés y los gastos militares españoles vinieron a sumarse terremotos y malas cosechas para incrementar las cargas del Tesoro. La única nueva fuente de rentas percibidas por la $\mathrm{Co}$ rona; $\tan$ necesitada de fondos, fue la venta de tierras eclesiásticas. En 1803, para aumentar el atractivo de estas tierras, la Corona revocó la prohibición de alterar los contratos de arrendamiento vigentes en las tierras desamortizadas ${ }^{41}$. Las ventas de tierras se convirtieron en una de las primeras fuentes de ingresos. Hacia 1808, aproximadamente, una sexta parte de las propiedades de la Iglesia se había vendido. Ello habría permitido la retirada del 75 por 100 de los vales en circulación ${ }^{42}$. En 1808 sólo se había amortizado un 14 por 100 , pero lo más importante para el gobierno era que esta nueva fuente de rentas eliminaba la necesidad de emitir más vales reales.

Resulta interesante la confrontación de los vales reales y los assignats, cuya amortización también debía realizarse mediante la venta de tierras eclesiásticas. En Francia, las ventas de propiedades de la Iglesia fueron lentas y todas las restantes fuentes de ingresos desaparecieron en la borrasca de la Revolución. El gobierno pasó a depender de la emisión de papel moneda, de lo

34 Canga Argüelles (1826), II, p. 165.

39 Hamilton (1944), p. 64.

* Artola (1982), pp. 450-453.

${ }^{41}$ Herr (1971), p. 53.

${ }^{42}$ Herr (1977), pp. 119-120. 
que resultó una rapidísima inflación de 1794 a 1796 . España no se hundió nunca en un caos revolucionario que destruyera las fuentes tradicionales de ingresos del gobierno, $y$, por consiguiente, la desamortización eclesiástica le permitió generar rentas suficientes para hacer frente a sus gastos de guerra $y$ evitar el total derrumbamiento en el valor del papel moneda.

Uno de los factores desencadenantes de la invasión francesa fue la decisión de Fernando VII de modificar el sistema fiscal vigente. Desconfiando de los antiguos consejeros de su padre, Fernando clausuró la Caja de Consolidación en 1808, poniéndola en manos del Consejo de Castilla. Esta medida alentó a los enemigos de la desamortización, pero también amenazó con reducir los ingresos del gobierno y menguar la ayuda que se daba a Francia ${ }^{43}$. Durante la invasión francesa, el profundo descuento de los vales reales fluctuó con los altibajos de la guerra. Las perspectivas de retirada de este papel moneda sólo progresaron con la llegada de Martín de Garay a la Secretaría de Hacienda en 1816. Pasado un año, Garay consiguió equilibrar el presupuesto mediante una estricta reducción de gastos. Durante los años 1816-1818 se retiraron otros 7 millones de pesos en vales reales. El carácter monetario de los vales quedó, finalmente, eliminado por un Decreto del 5 de agosto de 1818 , en virtud del cual los restantes 118 millones en vales se añadieron a la Deuda Pública ${ }^{44}$.

\section{Análisis de la inflación de los vales reales}

Bajo cualquier criterio, los precios se elevaron menos de lo previsible según una teoría cuantitativa simple, según la cual si output y velocidad son constantes, las alteraciones en la cantidad de dinero se traducen en inflación. Entre 1780 y 1800 , el volumen de vales reales en circulación aumentó un 1.039 por 100 , mientras que los precios en términos de papel moneda sólo subieron un 244 por 100 . Incluso durante la crisis de los años 1790 nos es de poca utilidad la teoría cuantitativa simple. Desde 1793 al fin del siglo, el papel moneda en circulación aumentó un 382 por 100 , mientras que los precios subieron más lentamente hasta un 177 por 100 . Pese a todo, se aceptaron por lo general las tesis de Hamilton, que hacen responsable a la inflación de las excesivas emisiones de papel moneda.

La hipótesis de Wallace ofrece una atractiva explicación alternativa al limitado incremento de los precios. El gobierno realizó numerosos intentos de preparar una ordenada retirada de los vales reales, pero las exigencias financieras de la guerra llevaron al Tesoro a echar mano frecuentemente de los

${ }^{43}$ Herr (1971), p. 93.

4 Plaza Prieto (1975), pp. 750-751; Canga Argüelles (1826), I, p. 174. 
fondos de amortización. Sólo cuando el público perdía confianza en las promesas del gobierno incidían los vales reales sobre los precios como auténtica moneda fiduciaria, pues, por lo demás, la imposición de tributos, vigentes y futuros, para retirarlos debía alterar la demanda de dinero y la velocidad, minimizando su efecto inflacionario.

Una sencilla verificación de esta hipótesis alternativa precisa de datos sobre los precios, el volumen de vales reales en circulación y algún indicio del compromiso gubernamental para su amortización. Ello nos permitiría utilizar el modelo aplicado por Bruce Smith a la Maryland colonial ${ }^{45}$. Tendría esto la ventaja de emplear como variable dependiente los datos sobre precios en lugar de los tipos de cambio que Smith se vio obligado a utilizar. Los datos sobre precios que proporciona Hamilton son muy superiores a los índices de la América colonial, pero no hay información consistente sobre el valor del fondo de amortización o las rentas anuales de la contribución que se le asignó para la retirada de los vales reales. A falta de esta información, he optado por emplear al modelo con una variable ficticia (dummy variable) para los años en que el gobierno amortizó una cantidad sustancial de vales reales:

$$
\text { Indice de precios } t=B_{0}+\sum_{i=0}^{2} B_{1 i}(\text { vales en circulación })_{t-i}+B_{2}(\text { dummy })_{t}+U_{t}
$$

En el período $1780-1800$, la variable ficticia tiene el valor de uno para 1785 y de cero para los años restantes. Aparte de estos cinco años, la retirada de vales reales fue insignificante. La única posible excepción es el año 1799 , en que se retiraron 360.000 pesos; pero esta acción quedó contrarrestada por la emisión de 53 millones de nuevos vales, que dieron un carácter muy distinto al mercado. El cuadro 2 ofrece la estimación por mínimos cuadráticos ordinarios del logaritmo natural de las variables como estimador aproximado de las tasas de variación ${ }^{46}$.

La estructura de los desfases en la relación del dinero sobre los precios es dudosa, y se registran tres regresiones con distintos desfases en las variables. Al parecer, la ecuación 3 es la preferible, dado que las dos variables con desfase rectifican la mayor parte de la correlación serial, como muestra el estadístico Durbin-Watson. Aunque sea ésta una prueba modesta de la hipótesis de Wallace, todas las ecuaciones sugieren que esta explicación no puede rechazarse. Los coeficientes de los vales reales son positivos y significativos,

15 B. Smith (1985 b).

4 Existen diferencias en cuanto a la cantidad de vales emitidos y retirados entre Hamilton (1947) y Herr (1977). Se han utilizado las cifras de Herr en los casos de divergencia porque tuvo acceso a mayor información. Con todo, al emplear los datos de Hamilton los resultados fueron muy similares. 


\section{CUADRO 2}

\section{Estimación minimo-cuadrática ordinaria de los determinantes de la inflación en España, 1780-1800}

\begin{tabular}{|c|c|c|c|}
\hline & Ecuación 1 & Ecuación 2 & Ecuacion 3 \\
\hline $\begin{array}{llllllllllll}\text { Constante } & \ldots & \ldots & \ldots & \ldots & \ldots & \ldots & \ldots & \ldots & \ldots & \ldots\end{array}$ & $\begin{array}{r}3,401 \\
(17,23)\end{array}$ & $\begin{array}{r}3,168 \\
(15,13)\end{array}$ & $\begin{array}{r}2,937 \\
(14,38)\end{array}$ \\
\hline 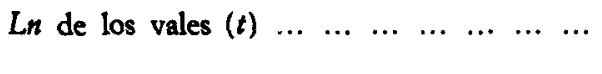 & $\begin{array}{r}0,433 \\
(7,84)\end{array}$ & $\begin{array}{l}0,373 \\
(2,87)\end{array}$ & $\begin{array}{r}0,293 \\
(2,48)\end{array}$ \\
\hline 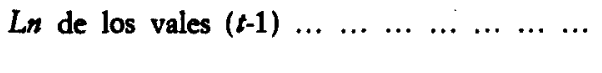 & & $\begin{array}{r}0,129 \\
(0,98)\end{array}$ & $\begin{array}{r}0,359 \\
(1,76)\end{array}$ \\
\hline$L n$ de los vales $(t-2) \ldots \ldots \ldots \ldots$ & & & $\begin{array}{r}-0,091 \\
(-1,79)\end{array}$ \\
\hline $\begin{array}{lllllllll}\text { Variable ficticia } & \ldots & \ldots & \ldots & \ldots & \ldots & \ldots & \ldots & \ldots\end{array}$ & $\begin{array}{r}-0,160 \\
(-1,60)\end{array}$ & $\begin{array}{r}-0,202 \\
(-2,35)\end{array}$ & $\begin{array}{l}-0,242 \\
(-3,21)\end{array}$ \\
\hline $\begin{array}{llllllllllllll}R^{2} & \ldots & \ldots & \ldots & \ldots & \ldots & \ldots & \ldots & \ldots & \ldots & \ldots & \ldots & \ldots\end{array}$ & 0,786 & 0,831 & 0,887 \\
\hline Estadistico Durbin-Watson $\ldots \ldots \ldots c c c c$ & 0,904 & 1,107 & 1,511 \\
\hline $\begin{array}{llllllllllll}\text { Estadístico } & F & \ldots & \ldots & \ldots & \ldots & \ldots & \ldots & \ldots & \ldots & \ldots\end{array}$ & 32,97 & 26,31 & 27,54 \\
\hline
\end{tabular}

La variable dependiente es el logaritmo natural del índice de precios en vales reales en Madrid. Las variables independientes son los logaritmos naturales de volumen de vales reales en circulación, contemporáneos y con desfases. La variable ficticia queda descrita en el texto. Los números entre paréntesis son los valores del estadístico $t$.

como era de esperar, pero la suma de los coeficientes es sustancialmente inferior a uno, de lo que se infiere que un aumento del 1 por 100 en la cantidad de dinero no se traducía en un incremento de los precios del 1 por 100 . Es posible que las variaciones en output puedan explicar algunas de las diferencias, pero ello supondría enormes e improbables aumentos de output. Es mucho más plausible que fuera el efecto del compromiso fiscal lo que hubiera afectado a la velocidad. En las tres ecuaciones, los signos negativos en el coeficiente de la variable ficticia parecen indicar que, en los años en que el gobierno retiró cantidades considerables de vales, todo incremento en su circulación habría tenido menores efectos sobre los precios que en los años en que el gobierno no cumplió sus compromisos.

Ello concuerda con la hipótesis de Wallace. Puesto que el carácter de los vales reales osciló entre moneda fiduciaria y dinero sólidamente respaldado, los aumentos en la cantidad de dinero tenían por fuerza que producir algún efecto en los precios. Ahora bien, dicho efecto quedaba considerablemente mi- 
tigado cuando el gobierno demostraba que tenía capacidad para pagar los intereses sobre los vales y para proceder metódicamente a su retirada. La previsión de nuevos impuestos dedicados a la amortización de papel moneda parece haber sido, por consiguiente, un importante factor a la hora de explicar la falta de reacción de los precios a las variaciones en la circulación de vales.

\section{Conclusión}

La emisión de papel moneda por parte del gobierno español, como en otros lugares de Europa y América, se consideraba una cuestión muy grave que exigía un plan de amortización concomitante. Las medidas fiscales adoptadas en pro de la futura amortización de vales reales tenían la virtud de restringir la demanda agregada y modificar la velocidad, contrarrestando con ello los efectos de una oferta monetaria en rápido aumento. No es seguro que, como implica la hipótesis de Wallace, estas medidas pudieran haber anulado completamente los efectos inflacionarios de los grandes incrementos en papel moneda. Pero sí parece que cuando el público estaba convencido de que el gobierno iba a realizar una retirada sistemática de vales, la inflación quedaba restringida. Sólo más tarde, cuando la quiebra política impidió al gobierno cumplir sus compromisos, se adapta la inflación de los vales reales más exactamente a las predicciones de una simple teoría cuantitativa. Una meticulosa concordancia de las políticas fiscal y monetaria demostró ser un medio eficaz en manos del gobierno para superar las crisis presupuestarias transitorias y evitar una inflación severa.

(Traducción de Eva Rodríguez HalfFTer.) 


\section{BIBLIOGRAFIA}

Artola, M. (1982): La Hacienda del Antiguo Régimen, Madrid.

BArRo, R. (1974): «Are Government Bonds Net Wealth?», Journal of Political Economy, LXXXII, 1095-1117.

Canga Argǘlles, J. (1826): Diccionario de Hacienda, Londres.

Hamilton, E. (1944): «War and Inflation in Spain, 1780-1800", Quarterly Journal of Economics, 59, 36-77.

- (1945): \&The Foundation of the Bank of Spain», Journal of Political Economy, LIII, 97.114.

- (1947): War and Prices in Spain, 1651-1800, Nueva York.

Harris, S. (1930): The Assignats, Cambridge.

Herr, R. (1971): «Hacia el derrumbe del Antiguo Régimen: crisis fiscal y desamortización bajo Carlos IV», Moneda y Crédito, 118, 37-100.

- (1977): «El experimento de los Vales Reales», en A. Otazu (ed.): Dinero y Crédito (Siglos XVI y XIX), Madrid, pp. 115-124.

Fernández Marugán, F., y Sch wartz, P. (1977): «El Ensayo de José Alonso Ortiz. Monetarismo smithiano en la España de los Vales Reales», en A. Otazu (ed.): Dinero y Crédito (Siglos XVI y XIX), Madrid, pp. 393-435.

Plaza Prieto, J. (1975): Estructura económica de España en el siglo XVIII, Madrid.

SARGENT, T. (1982): «The Ends of Four Big Inflations", en R. Hall (ed.): Inflation: Causes and Effects, Chicago, pp. 41-98.

Smit H, A. (1776-1937): The Wealth of Nations, Nueva York.

Sмгтн, B. (1984): «Money and Inflation in Colonial Massachusetts», Federal Reserve Bank of Minneapolis Quarterly Review, 1-14.

- (1985 a): «American colonial monetary regimes: the failure of the quantity theory and some evidence in favor of an alternate view», Canadian Journal of Economics, XVII, 531-565.

- (1985 b): «Some Colonial Evidence on Two Theories of Money: Maryland and the Carolinas», Journal of Political Economy, XCIII, 1178-1211.

Tinoco Rubinles, S. (1982): «Capital y crédito en la Baja Andalucía durante la crisis del Antiguo Régimen*, en J. Fontana (ed.): La economia española al final del Antiguo Régimen. IIII. Comercio y Colonias, Madrid, pp. 249-388.

Vicens Vives, J., y Nadal Oller, J. (1979): Manual de Historia Económica de España, Barcelona.

Wallace, N. (1981): \&A Modigliani-Miller Theorem for Open-Market Operations», American Economic Review, LXXI, 267-274.

W H ITE, E. (1985): «Financing the French Revolution: A New Look at the Assignat Inflation» (mimeo).

WICKER, E. (1985): «Colonial Monetary Standards Contrasted: Evidence from the Seven Years' War», Journal of Economic History, XLV, 869-884.

WEST, R. (1978): *Money in the Colonial American Economy», Economic Inquiry, XVI, 1-15. 